\title{
Telemedicine
}

\section{What have we learned?}

P. Whitten; B.Holtz; C. LaPlante

Michigan State University

\section{Keywords}

Telemedicine, telehealth, e-health

\section{Summary}

As the health care industry is facing many challenges and is undergoing extensive change, telemedicine is in the position to address these challenges and be an important part of health care's development. Telemedicine has been used for approximately a half century, in which researchers have explored the different technologies utilized, clinical outcomes, cost benefits, perceptions, and adoption challenges of its use. This paper reviews and summarizes these findings and presents possible future research endeavors. Examining what is known about telemedicine can aid in the development of innovative, sustainable and beneficial health technologies that could positively impact health care delivery and outcomes.

\section{Correspondence to:}

Pamela Whitten, PhD

Dean

College of Communication Arts \& Sciences

East Lansing, MI 48824-1212

pwhitten@msu.edu

\author{
Appl Clin Inf 2010; 1: 132-141 \\ doi: 10.4338/ACI-2009-12-R-0020 \\ received: December 4, 2009 \\ accepted: April 15, 2010 \\ published: May 5, 2010
}

Citation: Whitten P, Holz B, LaPlante C. Telemedicine what have we learned? Appl Clin Inf 2010; 1: 132-141 http://dx.doi.org/10.4338/ACI-2009-12-R-0020 


\section{Introduction}

Telemedicine - the use of telecommunications technology to provide health care over a distance was first documented in the late 1950's when a Nebraska psychiatrist connected to a prison over 150 miles away using closed circuit television to provide mental health services to the inmates [1]. Now the utilization of telecommunications technologies is practiced worldwide in virtually every specialty and is becoming more ubiquitous through use of consumer personal electronics [2-4]. Over the years, there have been different terms utilized to describe this practice. The term telehealth was developed to include healthcare and specialties such as nursing, mental health and nutrition that do not always provide clinical services. Cybermedicine and e-health are also commonly used terms, but typically describe health care delivered through the Internet [5]. This paper, consistent with Maheu, Whitten, and Allen's [6] definition, uses the term telemedicine to encompass the provision of health care services, clinical information, and education in all specialties over a variety of technologies including the Internet, mobile phones and electronic medical records. Telemedicine is continuing to grow due to the expansion of broadband infrastructures and the reduction of technology costs. The use of technology in a health care setting is also gaining increasing recognition and use in managing the changing state of health care and its many challenges.

While telemedicine can assist in augmenting, improving access to, and improving the quality of care, it is not a silver bullet. Close to fifty years of research can elucidate what is known, but it also points to areas in which further inquiry is needed. This paper is intended to provide a framework of understanding for those interested in or currently researching this field. First, the methodology utilized in this review is discussed, followed by an overview of telemedicine technologies and a summary of past telemedicine research, and lastly, avenues for future research are highlighted.

\section{Methodology}

A literature review was conducted to attain the articles referenced within this paper. Researchers searched the online databases of PubMed and Web of Science. Keywords used included "telemedicine and clinical outcomes", "telemedicine and health outcomes", "telemedicine cost", "telemedicine cost-effectiveness", "telemedicine patient perceptions", "telemedicine provider perceptions", "telemedicine patient satisfaction", "telemedicine provider satisfaction", "telemedicine adoption", and "telemedicine utilization". In each of these searches, telemedicine was also replaced with "telehealth" to account for variation in language used. From the articles retrieved, those relevant to this paper were included, with a focus on recent research to ensure the conclusions made were up-todate. Additionally, care was taken to ensure that selected articles encompassed research performed both in the United States and internationally in order to provide a broad perspective on the use of telemedicine.

\section{Telemedicine Solutions}

In the past, telemedicine technologies have been separated into two categories: synchronous and asynchronous telecommunication solutions. However, current technologies are converging, allowing an application to be both interactive and real-time, while also storing data for future use and review. This section will highlight some of these telemedicine technologies, their uses, and future possibilities in health care.

\subsection{Synchronous technologies}

The first technologies utilized in telemedicine were synchronous, through a system of cameras and televisions; psychiatrist visits were performed in real-time spanning a geographic distance of over 100 miles [1]. This type of consultation, which can use videoconferencing technology through mobile units, desktop units, or videophones, is still in regular use today and can also include the use of additional peripheral equipment to better enhance the medical care. Some examples of these pe- 
ripherals include (tele)stethoscopes, (tele)otoscopes, and (tele)dermascopes, allowing the far-side physician to examine the patient effectively. Today one of the most popular applications for telemedicine through videoconferencing is telepsychiatry [7]. Some other examples of synchronous telemedicine applications include pediatric emergency consults [8], diagnosis and treatment of strokes [9], teledialysis [10] and teledermatology [11]. This use of technology can potentially save the patient time and improve their access to care and quality of life. While synchronous technology is often what is imagined when thinking about telemedicine, there are also many applications that are asynchronous.

\subsection{Asynchronous Technology}

The use of asynchronous, or store-and-forward, technologies for health care is increasingly widespread, especially in image transfer and remote monitoring of chronic conditions [12]. This type of technology allows the patient image (e.g., mammogram, MRI) or data to be recorded at one point in time and viewed by a specialist or other health care provider at another time and location. Through technological advances, such as improved broadband infrastructure, high-definition viewing monitors, and high electronic storage capacities, the transfer of digital images is growing and changing the radiology field [13].

A store-and-forward application that is growing in popularity is remote monitoring or hometelecare This allows patients to upload specific health readings, such as blood pressure, weight, and glucose readings, from their home to their health care provider over a phone line or Internet connection [14]. Many remote monitoring systems can flag and alert health providers, caretakers, and patients if a reading is out of the patient's normal range [15]. Remote monitoring has had a significant impact on the hospital re-admittance rate, specifically emergency department admittance, of patients with congestive heart failure (CHF) [16]. Remote monitoring of CHF patients can alert both the health care providers and individuals of an impending episode and prevent an emergency incident before it happens [16-17]. As chronic diseases are becoming more prevalent, remote monitoring can provide an important platform for disease management and encourage prevention behaviors.

\subsection{The Future of Health Technologies}

The current technologic solutions appear to be heading toward a hybrid of synchronous and asynchronous methods of delivering health care in the future. As many telecommunication applications are converging, it is becoming more difficult to have a strict definition of the types of technology. This paper hopes to broaden the view of telemedicine and expand it through use of new technologies and innovative solutions. For example, exploratory research has suggested that an automated mobile phone text messaging system provides a dynamic, interactive platform for the patient to manage their health and also stores the information for the provider to view at a later time [18]. Another new trend many scientists are working on is the development and testing of types of wireless "smart" sensors for monitoring the health status of individuals. These sensors are non-invasive or minimally invasive and provide real-time monitoring of patient vitals, such as heart rate, blood pressure, falls, temperature, perspiration and blood glucose [19]. Some examples of these sensors include a "smart band-aid," digital pills, and clothing that is embedded with nano sensors [20]. While these sensors may be shifting the way that health care is delivered, they first must be assessed for data accuracy and quality assurance. Sriram and colleagues [21] suggest that there are three components that determine the complete accuracy and data quality of sensors: sensor factors, human factors and system architecture. Technology will continue to be an important tool for health care delivery, as past research has suggested that hospitals that are more "wired" have a better customer satisfaction rating [22]. 


\section{Past Telemedicine Research}

To date, research regarding telemedicine has provided valuable data on its uses, outcomes and costs. As each country has specific health, policy and structural issues it is difficult to generalize the data from one country to another, however, there seem to be some common trends that emerge throughout telemedicine research [23]. Many of the systematic reviews cited are examining telemedicine interventions worldwide. These have examined the clinical outcomes, cost benefits, perceptions and satisfaction of providers and patients, as well as the adoption of telemedicine.

\subsection{Clinical Outcomes}

A plethora of research has attempted to document the effectiveness of telemedicine across a wide range of disciplines. Positive clinical effects have been found for heart disease and psychiatric conditions, with observed improvements in medication compliance, heart failure outcomes, and hospital re-admission or emergency visits [24]. Another broad meta-analysis of telemental health applications for a wide variety of disorders determined $83 \%$ of the surveyed articles demonstrated clinically successful or potentially successful outcomes [25]. Successful use of telemedicine in terms of clinical and administrative outcomes was documented for child psychiatry, treatment of depression, panic/phobias, and other disorders [25-26]. However, there are many limitations to telemedicine studies that have been conducted, which make it difficult to truly assess these outcomes, including small sample size and lack of randomization. Collecting comparable data seems to present some difficulties in assessing a change in health outcomes. For example, a meta-analysis of home telehealth demonstrated an overall moderate, positive, and significant effect on clinical outcomes [24], but it is difficult to know if this was due to more attention being paid to patients by the health care providers. A systematic review of telemedicine in Asian countries found there was very little use of control groups, which makes it difficult to understand its role in health outcomes [26-27].

Some research has sought to demonstrate the equivalence between telemedicine care and traditional care, however, further research still needs to be conducted [24]. Studies have reported cognitive behavior therapy [28-30], epilepsy [31], and minor injuries care [32] via telemedicine are equal to traditional care. These non-significant differences are key in establishing that the provision of care through the use of telemedicine has no effect on the clinical outcomes and can be just as beneficial. Nevertheless, while attempting to demonstrate equivalence in telemedicine interventions, it is important to note that not all studies have been able to achieve this goal [33].

\subsection{Cost-Effectiveness}

Evidence for the cost-effectiveness of telemedicine is mixed, and many authors conclude there is not sufficient data to determine the true economic impact [e.g., 34-35]. One review of the telehomecare literature concluded that cost-effectiveness analysis has increased in recent years, although it is hard to synthesize due to a lack of consistency across economic indicators used [36]. A systematic review of cost-effectiveness in telemedicine interventions conducted in 2002 indicated there was no solid evidence that telemedicine provides a cost-effective solution for delivering health care [37]. This review determined that $83 \%$ of the articles provided a basic cost information; $29 \%$ examined the type of utilization that would be necessary to be more cost-effective than traditional care, and none of them addressed the issue at the level of detail necessary to answer that question; and lastly, none of the articles performed a sensitivity analysis, which is needed when reviewing cost benefit [37]. A study examining only Asian telemedicine programs found similar results [27]. However, Rojas and Gagnon [36] performed a telehomecare literature review in 2007, which determined that $91 \%$ of the articles they analyzed established that the evaluated programs were cost-effective. Many articles that posit cost-effectiveness analysis tend to be limited by small sample sizes and evaluations performed over a short period of time $[27,36,38]$. In order to fully demonstrate costbenefit, the telemedicine interventions should include larger sample sizes, economic sensitivity analysis and longitudinal data [38]. 


\subsection{Patient and Provider Perceptions}

A great deal of research has established high patient satisfaction with a variety of care received via telemedicine $[10,17,39]$. Patients the world over have reported satisfaction with various telemedicine programs, in countries like Italy [40], Scotland [41], South Korea [42], India [43], and Finland [44]. After experiencing a telemedicine visit, these patients have reported they would use this type of technology again [45]. However, this is not always the case, as some studies have shown that patients are not always satisfied with telemedicine, often due to problems they experience with operating the technology [46-48].

Research has also demonstrated overall satisfaction among health care providers and that their general acceptance of the technology is positive, if not high [49-50]. Studies have indicated that providers have positive perceptions about the delivery of care through telemedicine [10], believe that telemedicine helped to improve their own skills [51], and would use it again [45]. Although it generally takes physicians longer to be satisfied with the technology, their satisfaction improves greatly over time and use [52]. Conversely, some studies have documented that not all health care providers are satisfied with telemedicine [53-54].

\subsection{Adoption and Utilization}

Telemedicine is flourishing globally, as it is next to impossible to count the number of programs that employ some form of it. Still, it is generally agreed that actual use of the technology by providers remains disappointing in the broad context of health care [55-56]. Providers have been called the "gatekeepers" of telemedicine [48], and many barriers have been cited that discourage use, such as perceptions of risk [57], unclear payment procedures, fears of technology failings [58], and licensure/credentialing and liability issues [59]. However, some research indicates that even when many of these barriers are accounted for, providers may still be reluctant to utilize telemedicine [59]. Because many telemedicine programs are located in rural areas, additional barriers may present themselves, such as a lack of technical staff, technology costs, inadequate broadband infrastructure, as well as uncertainties about costs $[60,55,61]$.

Whitten and Holtz [59] state about future costs that in order to address provider barriers, certain steps should be taken when implementing telemedicine programs, such as: seeking to understand the interrelationship between technology use, work context, and the negotiation of work roles for each telemedicine application; determining how to support changes in work routines; gaining leadership involvement; and exploring the proper alignment of incentives. Other researchers have recommended additional education and training for health care providers [62], involving key stakeholders early and attaining champions [63], piloting programs on a small scale, evaluating past telemedicine interventions, and ensuring that technology is convenient, easy to use and accessible [64].

\section{Future Research}

There are still many issues that need to be addressed through research in the coming years; this section will provide possible future research trends, such as organizational issues, use of consumer electronics, and the potential impact of social media on telemedicine.

\subsection{Organizational Issues}

One of the main challenges with installing and deploying any type of telemedicine application is the nature of the health system itself. Within any health system, it may be extremely difficult to change work processes and perceptions of telemedicine. Organizations that are developing or operating a telemedicine program may often face many internal challenges. A study that examined existing U.S. telemedicine programs indicated that these are most successful when they are formally structured, innovative, and work to improve patient care [65-66]. Due to the disparate health system in the U.S., there are unique challenges when developing a telemedicine protocol that includes patients being seen by different providers, scheduling, and reimbursement issues. However, many of these 
recommendations can be applied to any program, as it requires an examination of the individual characteristics of each organization.

Perhaps because of the slow implementation and high costs of large-scale technological deployments, many are beginning to explore the use of consumer electronics to monitor individuals' health.

\subsection{Consumer electronics}

A growing trend in telemedicine and health care in general is the use of consumer electronics to monitor, store and communicate in new ways regarding an individual's health. These new consumer technologies include web-based personal health records (PHR), MP3 players, mobile phones, and social media applications. For example, GoogleHealth and Microsoft HealthVault allow an individual to input their own health data, check for allergy alerts, manage prescriptions, and store test results. Other personal devices have been developed, such the Nike+ iPod sportskit. This device can track runs/walks, goals and progress.

Currently, it seems some of the most popular electronics used in health are mobile phones and social media applications. Mobile phones are quickly becoming ubiquitous in the United States and have been extremely popular in many parts of the world for several years. Numerous health care providers and researchers believe that mobile phones can be an excellent tool for health interventions, as they can provide a targeted and interactive platform. The popular nature of mobile phones worldwide has facilitated many health interventions and applications. For example, mobile phones have been used in the areas of asthma, diabetes, weight/nutrition, smoking cessation, sexual health information, medication and appointment reminders [67]. In diabetes management, mobile technologies have been utilized in many ways, such as: SMS (text messaging) applications used to provide information, record blood-glucose readings, and provide feedback [68-70]; a mobile phone with a blood-glucose tester integrated onto the battery pack of a phone [71]; a study that employed a cable connecting the phone to a diabetes blood glucose tester [72]; and equipping the phone and tester with Bluetooth ${ }^{\circledR}$ technology [73]. These studies mainly explored patient compliance, acceptance and satisfaction, all of which were rated highly. A recent literature review of telemedicine delivered via mobile phones found evidence of positive effects on asthma symptoms, stress levels, and smoking cessation outcomes [67]. However, most of these studies had small sample sizes, suggesting additional research with larger sample sizes and control groups are necessary to determine the true effects.

\subsection{Social Media in Health}

As technology is shifting social media may be considered to be a tool in telemedicine (or e-health). In recent years, the use of social media has exploded. Social media is a form of instant and interactive mediated communication that is developed, edited, and utilized by individuals through the Internet and is facilitated by Web 2.0. Social media facilitates the transformation of information from a monologue to a dialogue [74-75]. Some of the most popular examples of social media include Facebook, MySpace, Twitter, YouTube, Second Life, Wikipedia, and podcasts. The increase in social media use has created a need for researchers to study this communication phenomenon, especially in the health arena. Thus far, the majority of studies exploring social media in health are not focused on developing interventions; instead, they examine already-occurring activities. These activities could augment and extend current telemedicine technologies and include disaster alerts and response, diabetes management, biomedical device capture and reporting, and post-discharge patient follow-up care, to name a few [76]. Social media is offering an avenue that has the potential to change the very paradigm of health care delivery and access. A challenge and criticism of using social media platforms for health has been the difficulty in establishing resource and information credibility of the authors of content.

While technology use in health care is exploding, its place in organizations, long-term effects, outcomes, reimbursement, and privacy issues still needs to be explored. 


\section{Conclusion}

Before advancing telemedicine research and its use in a way that moves the medical practice and research arena forward, it is important to examine what is already known. Telemedicine has a fiftyyear history and, as technology is evolving and the health care system will most likely be changing dramatically, it is key to recognize what has been successful in the past. The utilization of technology in the health system has been slow, but continued adoption of telemedicine does show promise to address significant barriers occurring in the health setting. Some promising areas of research include examining new technologies and how they can improve access and quality, as well as their societal implications. Previous telemedicine research has been reported to provide similar (and sometimes improved) clinical outcomes compared to traditional care, and has also demonstrated some cost savings. In these next fifty years, it will be important to understand and provide solutions to the current perceived barriers to the use of new telecommunication technologies in health care. It is our hope that this paper will encourage and propel the field of telemedicine research by providing a framework of past research and findings along with highlighting some new opportunities for innovative research.

\section{Clinical Relevance Statement}

This review sought to provide practitioners and consumers with a summary of what telemedicine research has shown to date. This allows key stakeholders to move forward in developing successful telemedicine programs and interventions. While new technologies are being implemented into health care, it is important to recognize the past challenges and solutions utilized to address them.

\section{Conflict of Interest Statement}

The authors declare that they have no conflict of interest related to this manuscript. They also state that there is no financial conflict of interest related to this manuscript.

\section{Human Subject Research Approval}

Not applicable. 


\section{References}

1. Wittson CL, Affleck DC, Johnson V. Two-way television in group therapy. Mental Hospitals. 1961; 12(10): 22-23.

2. Whitten P, Goolittle G, Hellmich S. Telehospice: Using telecommunication technology for terminally ill patients. JCMC [Internet]. 2001 Jul [cited 2010 Feb 6]; 6(4). Available from http://jcmc.indiana.edu/vol6/issue4/whitten2.html

3. Grigsby J. Telemedicine: Where it is and where it's going. Annals of Internal Medicine 1998; 129(2): 123127.

4. Craig J, Patterson V. Introduction to the practice of telemedicine. Journal of Telemedicine and Telecare 2005; 11: 3-9.

5. McLendon K. E-commerce and HIM: Ready or not, here it comes. Journal of the American Health Information Management Association 2000; 71(1): 22-23.

6. Maheu MM, Whitten P, Allen A, editors. E-health, telehealth, and telemedicine: A guide to start-up and success. Jossey-Bass; 2001.

7. Hilty DM, Yellowles PM, Cobb HC, Bourgeois JA, Nuefeld, JD, Nesbitt TS. Models of telepsychiatric consultation - Liaison service to rural primary care. Psychosomatics 2006; 47: 152-157.

8. Heath B, Salerno R, Hopkins A, et al. Telemedicine for pediatric critical care consultation. Pediatr Crit Care Med 2009; 10(5): Epub 2009 May 15; doi:10.1097/PCC.0b013e3181a63eac.

9. Levine SR, Forman M. "Telestroke": The application of telemedicine for stroke. Stroke 1999; 30: 464-469.

10. Whitten P, Buis L. Use of telemedicine for haemodialysis: perceptions of patients and health-care providers, and clinical effects. J Telemed Telecare 2008; 14: 75-78.

11. Burdick AE. Teledermatology: Extending specialty care beyond borders. Archives of Dermatology 2007; 143(12): 1581-1582.

12. Pare G, Jaana M, Sicotte C. Systematic review of home telemonitoring for chronic diseases: The evidence base. Journal of the American Medical Informatics Association 2007; 14(3): 269-277.

13. Steinbrook, R. The age of teleradiology. The New England Journal of Medicine 2007; 357: 5-7.

14. Field MJ, Grigsby J. Telemedicine and remote patient monitoring. JAMA 2002; 288: 423-425.

15. Crossley G, Boyle A, Vitense H, Sherfesse L, Hardwin Mead, R. Trial design of the clinical evaluation of remote notification to reduce time to clinical decision: The clinical evaluation of remote notification to reduce time to clinical decision (CONNECT) study. American Heart Journal 2008; 156(5): 840-846.

16. Whitten P, Bergman A, Meese MA, Bridwell K, Jule K. St. Vincent's home telehealth for congestive heart failure patients. Telemedicine and e-Health 2009: 15(2): 148-153.

17. Whitten P, Mickus M. Home telecare for COPD/CHF patients: Outcomes and perceptions. Journal of Telemedicine and Telecare 2007; 13: 69-73.

18. Holtz B, Whitten P. Managing asthma with mobile phones: A feasibility study. Telemedicine and eHealth 2009; 15: 907-909.

19. Harasanyi G. Sensors in biomedical application: May they change the quality of life. Sensor Review 2001: 21(4): 259-267.

20. Topol EJ. The new healthcare: Smart band aids, digital pills, wrist bands. 2009 Sept 30 [cited 2009 Nov 21]; Venture Beat. Available from: http://venturebeat.com/2009/09/20/the-new-healthcare-smart-bandaids-digital-pills-wrist-bands-promise-to-track-your-health/

21. Sriram J, Kotz D, Rahan A, Sastry M, Yarvis M. Challenges in data quality assurance in pervasive health monitoring systems. Paper presented at the Future of Trust In Computing conference; June/July 2008; Berlin, Germany.

22. Whitten P, Mylod D, Gavran G, Sypher H. "Most Wired Hospitals" rate patient satisfaction. Communications of the ACM 2008; 51(4): 96-102.

23. Håkansson S, Gaveline C. What do we really know about the cost effectiveness of telemedicine. Journal of Telemedicine and Telecare 2000; 6(Suppl. 1): 133-136.

24. DelliFraine JL, Dansky KH. Home-based telehealth: A review and meta-analysis. J Telemed Telecare 2008; 14(2): 62-66.

25. Hailey D, Roine R, Ohinmaa A. The effectiveness of telemental health applications: A review. Can J Psychiatry 2008; 53(11): 769-778.

26. D'Souza R. Telemedicine for intensive support of psychiatric inpatients admitted to local hospitals. J Telemed Telecare 2000; 6(Suppl. 1): 26-28.

27. Durani H, Khoja S. A systematic review of the use of telehealth in Asian countries. Journal of Telemedicine and Telecare 2009; 15: 175-181.

28. Lovell K, Cox D, Haddock G, Jones CE, Raines D, Garvey R, et al. Telephone administered cognitive behaviour therapy for treatment of obsessive compulsive disorder: randomised controlled non-inferiority trial. BMJ 2006; 333(7574): 883. 
29. De Las Cuevas C, Arredondo MT, Cabrera MF, Sulzenbacher H, Meise U. Randomized clinical trial of telepsychiatry through videoconference versus face-to-face conventional psychiatric treatment. Telemed J E Health 2006; 12(3): 341-50.

30. Nelson EL, Barnard M, Cain S. Feasibility of telemedicine intervention for childhood depression. Counselling and Psychotherapy Research. 2006; 6(3): 191-195.

31. Rasmusson KA, Hartshorn JC. A comparison of epilepsy patients in a traditional ambulatory clinic and a telemedicine clinic. Epilepsia 2005; 46(5): 767-770.

32. Benger JR, Noble SM, Coast J, Kendall JM. The safety and effectiveness of minor injuries telemedicine. Emerg Med J 2004; 21(4): 438-445.

33. Jenkins RL, McSweeney M. Assessing elderly patients with congestive heart failure via in-home interactive telecommunication. J Gerontol Nurs 2001; 27: 21-27

34. Davalos, ME, French, MT, Burdick, AE, Simmons, SC. Economic evaluation of telemedicine: Review of the literature and research guidelines for benefit-cost analysis. Telemed J E Health 2009; 15(2): 933-948.

35. Kairy D, Lehoux P, Vincent C, Visintin M. A systematic review of clinical outcomes, clinical process, healthcare utilization and costs associated with telerehabilitation. Disabil Rehabil 2009; 31(6): 427-447.

36. Rojas SV, Gagnon MP. A systematic review of the key indicators for assessing telehomecare costeffectiveness. Telemed J E Health 2008; 14(9): 896-904.

37. Whitten P, Mair F, Hatcox A, May C. Williams T, Hellmich S. Systematic review of cost-effectiveness: Studies of telemedicine interventions. BMJ 2002; 324: 1434-1437.

38. Jennett PA, Scott RE, Affleck Hall L, Hailey D, Ohinmaa A, Anderson C, et al. Policy implications associated with the socioeconomic and health system impact of telehealth: A case study from Canada. Telemed J E Health 2004; 10(1): 77-83.

39. Myers KM, Valentine JM, Melzer SM. Child and adolescent telepsychiatry: utilization and satisfaction. Telemed J E Health 2008; 14(2): 131-137.

40. Favero L, Pavan L, Arreghini A. Communication through telemedicine: home teleassistance in orthodontics. Eur J Paediatr Dent 2009; 10(4): 163-167.

41. Heaney D, Caldow J, McClusky C, King G, Webster K, Mair F, et al. The introduction of a new consulting technology into the National Health Service (NHS) for Scotland. Telemed J E Health 2009; 15(6): 546551.

42. Cho JH, Lee HC, Lim DJ, Kwon HS, Yoon KH. Mobile communication using a mobile phone with a glucometer for glucose control in Type 2 patients with diabetes: as effective as an Internet-based glucose monitoring system. J Telemed Telecare 2009; 15(2): 77-82.

43. Mishra A, Kapoor L, Mishra SK. Post-operative care through tele-follow up visits in patients undergoing thyroidectomy and parathyroidectomy in a resource-constrained environment. J Telemed Telecare 2009; 15(2): 73-76.

44. Lemmetty R, Mäkelä K. Mobile digital fundus screening of type 2 diabetes patients in the Finnish county of South-Ostrobothnia. J Telemed Telecare 2009; 15(2): 68-72.

45. Varkey P, Schumacher K, Swanton C, Timm B, Hagen PT. Telemedicine in the work site: a study of feasibility, and patient and provider satisfaction. J Telemed Telecare 2008; 14(6):322-325.

46. Paul PG, Raman R, Rani PK, Deshmukh H, Sharma T. Patient satisfaction levels during teleophthalmology consultation in rural South India. Telemed J E Health 2006; 12(5): 571-578.

47. Duke C. The Frail Elderly Community-Based Case Management Project. Geriatr Nurs 2005; 26(2): 122127.

48. Smith GE, Lunde AM, Hathaway JC, Vickers KS. Telehealth home monitoring of solitary persons with mild dementia. Am J Alzheimers Dis Other Demen 2007; 22: 20-26.

49. Whitten PS, Mackert MS. Addressing telehealth's foremost barrier: provider as initial gatekeeper. Int J Technol Assess Health Care 2005; 21(4): 517-521.

50. Moreno D, Ferrándiz L, Pérez-Bernal AM, Ríos JJ, Carrasco R, Camacho F. Evaluation of a screening system for patients with pigmented lesions using store-and-forward teleconsultation. Actas Dermosifiliogr 2005; 96(4): 222-230.

51. Al-Kadi A, Dyer D, Ball CG, McBeth PB, Hall R, Lan S, et al. User's perceptions of remote trauma telesonography. J Telemed Telecare 2009; 15(5): 251-254.

52. Whitten P, Buis L, Love B. Physician-patient e-visit programs: Implementation and appropriateness. Disease Management \& Health Outcomes 2007; 15(4): 207-214.

53. Mair FS, Goldstein P, May C, Angus R, Shiels C, Hibbert D, et al. Patient and provider perspectives on home telecare: preliminary results from a randomized controlled trial. J Telemed Telecare 2005; 11 (Suppl. 1): 95-97.

54. Collins K, Bowns I, Walters S. General practitioners' perceptions of asynchronous telemedicine in a randomized controlled trial of teledermatology. J Telemed Telecare 2004; 10(2): 94-98.

55. Wang Z, Gu H. A review of telemedicine in China. J Telemed Telecare 2009; 15(1): 23-27. 
56. Kerr K, Norris T. Telehealth in New Zealand: current practice and future prospects. J Telemed Telecare. 2004; 10 (Suppl. 1): 60-63.

57. Mair F, Finch T, May C, Hiscock J, Beaton S, Goldstein P, et al. Perceptions of risk as a barrier to the use of telemedicine. J Telemed Telecare 2007; 13(Suppl. 1): 38-39.

58. Cloutier P, Cappelli M, Glennie JE, Keresztes C. Mental health services for children and youth: a survey of physicians' knowledge, attitudes and use of telehealth services. J Telemed Telecare 2008; 14(2): 98-101.

59. Whitten P, Holtz B. Provider utilization of telemedicine: the elephant in the room. Telemed J E Health. 2008; 14(9): 995-997.

60. Whitten P, Buis L. Private payer reimbursement for telemedicine services in the United States. Telemed J E Health 2007; 13(1): 15-23.

61. Dyb K, Halford S. Placing globalization technologies: Telemedicine and the making of difference. Sociology 2009; 43: 232-249.

62. de Bustos EM, Moulin T, Audebert HJ. Barriers, legal issues, limitations and ongoing questions in telemedicine applied to stroke. Cerebrovasc Dis 2009; 27 (Suppl. 4): 36-39.

63. Schmeida M, McNeal R, Mossberger K. Policy determinants affect telehealth implementation. Telemed J E Health 2007; 13(2): 100-107.

64. Smith AC. Telemedicine: challenges and opportunities. Expert Rev Med Devices 2007; 4(1): 5-7.

65. Whitten P, Holtz B, Young R, Davis S. The organizational structure and architecture of telemedicine: Keys to success. Paper presented at the 2009 American Telemedicine Association Conference. 2009 April; Las Vegas, Nevada.

66. Whitten P, Holtz B, Nguyen L. Keys to a Successful and Sustainable Telemedicine Program. International Journal of Technology Assessment in Health Care. Forthcoming 2010.

67. Krishna S, Boren SA, Balas EA. Healthcare via cell phones: a systematic review. Telemed J E Health 2009; 15(3): 231-240.

68. Ferrer-Roca O, Cardenas A, Diaz-Cardama A, Pulido P. Mobile phone text messaging in the management of diabetes. J Telemed Telecare 2004: 10(5): 282-286.

69. Franklin V, Waller A, Pagliari C, Greene S. "Sweet Talk": Text messaging for intensive insulin therapy for young people with diabetes. Diabetes Technology \& Therapeutics. 2003; 6(6): 991-996.

70. Wangberg SC, Arsand E, Andersson N. Diabetes education via mobile text messaging. J Telemed Telecare. 2006; 12(S1): 55-56.

71. Carroll AE, Marrero DG, Downs SM. The HealthPia GlucoPack Diabetes Phone: a usability study. Diabetes Technology \& Therapeutics. 2007; 9(2): 158-164.

72. Farmer, AOG, Hayton P, Bryden K, Dudley C, Neil A et al. (2005). A real-time, mobile phone-based telemedicine support system to support young adults with type 1 diabetes. Informatics in Primary Care. 2005; 13; 171-177.

73. Gammon D, Arsand R, Walseth OA, Andersson N, Jenssen M, Taylor T. Parent-child interaction using a mobile and wireless system for blood glucose monitoring. Journal of Medical Internet Research 2005; 7(5): e57.

74. Rhee Y, Kang H, Kim Y, Lee J, Chang I. Expanding SNS features with CE devices: Space, profile, communication. In Human Interface and the Management of Information. Proceedings of the Symposium on Human Interface; 2009; San Diego, CA. Berlin/Heidelberg: Springer; 2009; 458-467.

75. Hoffman D, Novak T, Chatterjee P. Commercial scenarios for the Web: Opportunities and Challenges. Journal of Computer Mediated Communication [Internet]. 1995[cited 2010 Feb 6];1(3). Available from: http://citeseerx.ist.psu.edu/viewdoc/download?doi=10.1.1.109.7778\&rep=rep1\&type=pdf

76. Terry M. Twittering healthcare: Social media and health care. Telemedicine and e-Health Journal 2009; 15: 507-510. 